\title{
A Simplified LED Converter Design and Implement
}

\author{
Yi-Hua Fan ${ }^{1}$, Cheng-Ju Wu²,Chen-Chao Fan², Kuo-Wei Chih ${ }^{3}$, Lun-De Liao ${ }^{3}$ \\ Chung Yuan Christian University \\ ${ }^{1}$ Corresponding Author (Assistant Professor of Department of Mechanical Engineering \\ and R\&D Center for Membrane Technology, Chung Yung Christian University) \\ ${ }^{2}$ Master and ${ }^{3}$ College (Student of Department of Mechanical Engineering)
}

\begin{abstract}
High power LED converter combined with switching power supply and current adjustment device for is presented. The switching power supply provides one stabilized voltage source, and the current adjustment device controls the output currents with a desired constant current and the over-load protection. The experiment results shows the circuit can work well and pass the load test and the electromagnetic interference test.
\end{abstract}

Keywords: forward power supply 、 LED controller 、 current controller

\section{Introduction}

Typically, LED performance is affected by the drive current and by the ambient temperature surrounding the LED. Both of these parameters contribute to the junction temperature of the LED, which affects the performance. In the consumption of under good heat dissipation condition, when applying white LEDs for display backlighting or other illumination applications, there are two reasons to drive them with constant current: one is to avoid violating the absolute maximum current rating and compromising the reliability; the second is to obtain predictable and matched luminous intensity and chromaticity from each LED. [1]

The power source of LED is for direct current and low voltage, therefore, in the tradition used power sources to impel of the tungsten lamp or the daylight lamp certainly does not suit directly impels the LED lamps and lanterns. There are three types of direct current power for the LED lamps: low-frequency transformer and half-wave or full-wave rectification electric circuit, switching power source supply with constant voltage or constant current. The switching power sources with constant voltage which technique is very mature and easy to obtain are the major part LED illumination power source way at present. There are many researches for this type of power supply [25]. But the current load is changeable for different LED load and the LED brightness is not easy to control, therefore, these is the defect for the type of solution to the LED illumination power source.
In this paper, we try to combine both switching power supply and current adjustment device for the LED converter. The circuit is divided to two parts. The switching power supply part is design as traditional. The design points are aimed at the stabilized voltage supply and the electromagnetic interference prevention. The current adjustment device is series connected with the switching power supply part. The design points are aimed at constant current adjusting and current protected. The experiment results shows the circuit can work well either apply to the 7- or 24-LEDs for different current condition for long time the load test. Furthermore, the total noise spectrum is lower than the CISPR conductive electromagnetic interference conduction launch target. The circuit passes the electromagnetic interference test.

\section{Circuit Design}

\subsection{Switching power supply circuit design}

The design flow chart of the LED converter is shown in Fig.1. Fig.2 is the LED converter circuit. Since the voltage of the city electricity by way of front extremely EMI filter and bridge type rectifier is great than the voltage loss of the LEDs, the part of switching power supply circuit is chosen as a buck converter. Thus, we choose a Forward converter as the part of switching power supplies circuit, but there is some different as a common Forward converter. Because the point of the LED driver is the stabilized current, the small change of source voltage is not a design issue, so we use logic IC to get a pulse signal and delete the output voltage feedback circuit. Furthermore, we insert a feedback resistance in the source pole of MOSFET to limit primary current $I_{D S}$, to avoid the demand due to the over load of $I_{D S}$.

In this circuit, the behavior of MOSFET is like a voltage control current source. Because the MOSFET is a Voltage-controlled current source element, so we can use the method of bias circuit to make a stable and predictable direct current operation point. The feedback resistance $\mathrm{R}_{f_{-} 1}$ will provide a feedback voltage to stable the direct current operation point. 
From the circuit of Fig.2, we can find :

$$
\begin{aligned}
& V_{s}=I_{D S} \times R_{f \_1} \\
& I_{D S} \uparrow \Rightarrow V_{s} \uparrow \Rightarrow \begin{array}{c}
\text { MOSFET control } \\
\text { and drive circuit }
\end{array} \Rightarrow V_{G}=0 \Rightarrow I_{D S} \downarrow \\
& I_{D S} \downarrow \Rightarrow V_{s} \downarrow \Rightarrow \begin{array}{c}
\text { MOSFET control } \\
\text { and drive circuit }
\end{array} \Rightarrow V_{G}=V \Rightarrow I_{D S} \uparrow
\end{aligned}
$$

Thus the current $I_{D S}$ can be adjusted by changing the feedback resistance and we can achieve the purpose of over load protected and power transformer primary power output control by tuning the magnitude of $I_{D S}$.

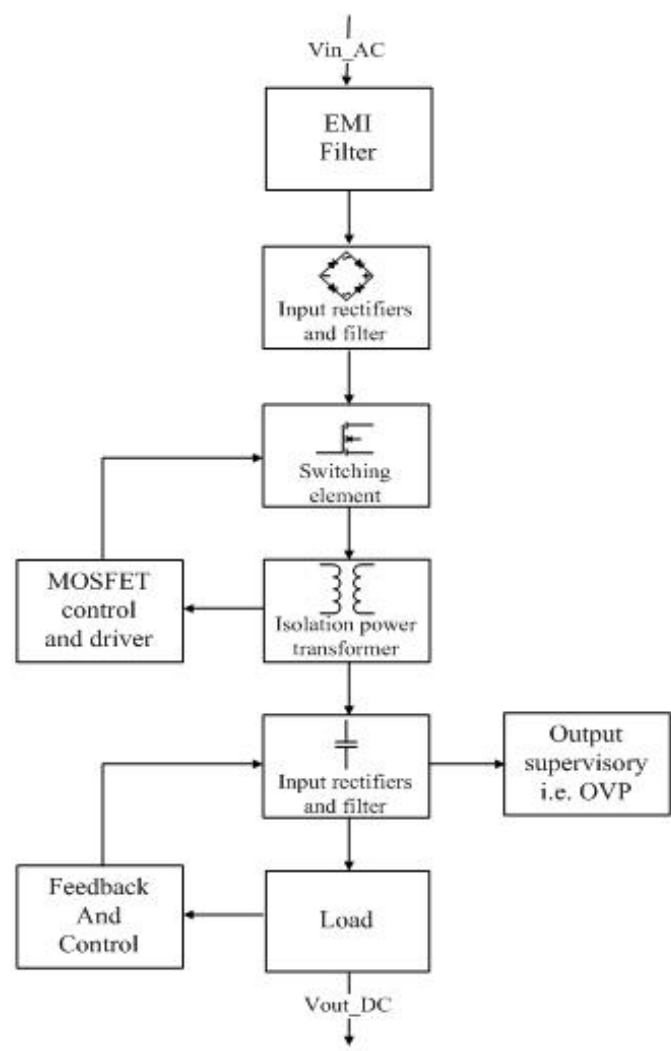

Fig.1 The Design Flow Chart of the LED Driver

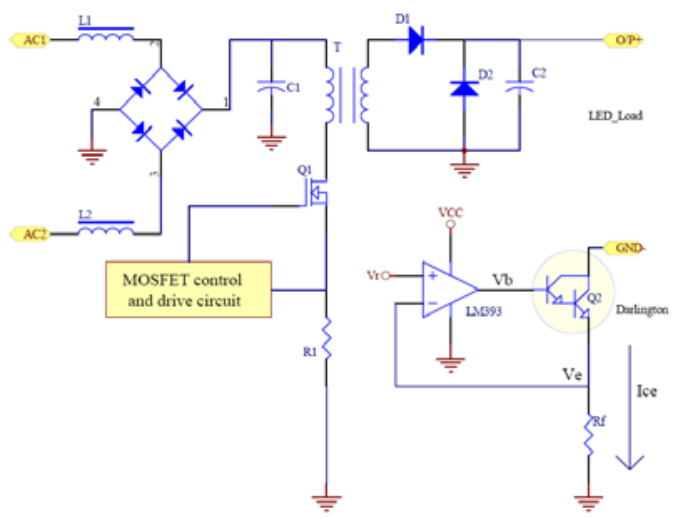

Fig.2 LED Driver Circuit

\subsection{LED current control circuit}

The secondary winding voltage of power transformer connects to the diode rectifier in series to form a halfwave rectifier and a capacitor in parallel connection to reduce the voltage ripple.

The output pole of LED Ground connects to a Darlington circuit then seriously connects a feedback resistance. When the Darlington circuit works, the LED load current $\mathrm{I}_{L}$ will cause a voltage loss $\mathrm{V}_{e}=$ $I_{L} \times R_{f_{-2}}$ at $\mathrm{R}_{f_{-2}}$. The voltage sends to a comparator to compare with the command voltage $V_{r}$ to control the Darlington circuit to achieve the purpose of a constant stable current output. Fig. 3 is the photograph of the current converter.

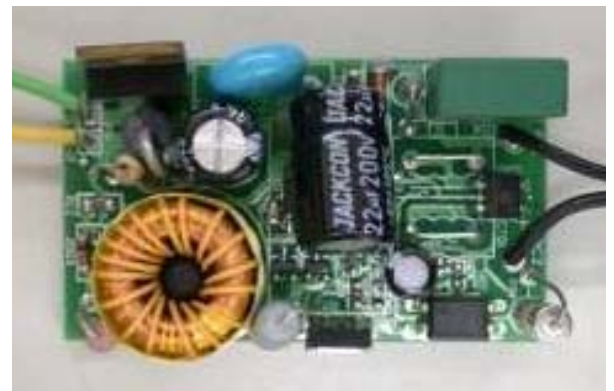

Fig.3 LED Current Converter

Since the Bipolar junction transistor is a base current $\left(\mathrm{I}_{b}\right)$ control collector current element, thus, we can control the LED current by the base current. The resistance $\mathrm{R}_{f_{-} 2}$ provides a feedback voltage $V_{e}$ signal in the circuit as shown in Fig.4. This voltage compares with the reference voltage $\mathrm{V}_{r}$, we can find : $V_{e}=I_{L} \times R_{f 2}$ If $I_{L} \uparrow \Rightarrow V_{e} \uparrow \Rightarrow V_{e}>V_{r} \Rightarrow V_{b}=0 \Rightarrow I_{L} \downarrow$ If $I_{L} \downarrow \Rightarrow V_{e} \downarrow \Rightarrow V_{e}<\mathrm{V}_{r} \Rightarrow V_{b}=V_{c c} \Rightarrow I_{L} \uparrow$

For different watt type of high power LEDs, adjusts $\mathrm{R}_{f_{2} 2}$ and $\mathrm{V}_{r}$ can control the magnitude of the load current.

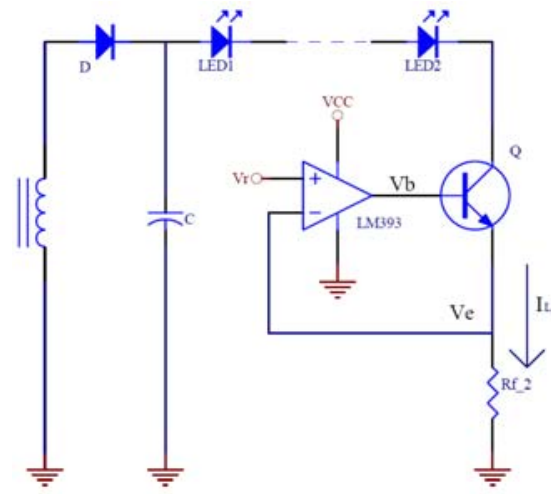

Fig.4 Voltage Control Current Source 


\section{Experiment Results}

We use the high power LEDs as the test piece. This type of LEDs has $350 \mathrm{~mA}$ forward current with one watt $-700 \mathrm{~mA}$ with $2 \mathrm{~W}$ and $1050 \mathrm{~mA}$ with $3 \mathrm{~W}$. Fig.5 is the frame of the test equipments. The illumination module of high power LEDs for test is the Luxeon ${ }^{\mathrm{TM}}$ Power Light Source produced by the Lumileds Lighting Company shown in Fig.6. The model number is 型LXHL-MWGC-Star-Hex. The white light LEDs with $V_{f}=3.6 \mathrm{~V}, I_{f}=350 \mathrm{~mA}$, light output=20 Lm. The test results are shown in Fig.7 and Fig.8 and the detail data are listed at Table1 and Table2.

Furthermore, the current driver operates at high frequency for slimming down the volume and weight. But the norm of electromagnetic interference will enhance. Thus we consider the prevention of conductive EMI as the circuit design. The EMI restriction element is added to the alternating current side. Fig.9 is the test result of the total noise frequency response. We can find the total EMI noise is under the limitation of laws and regulations.

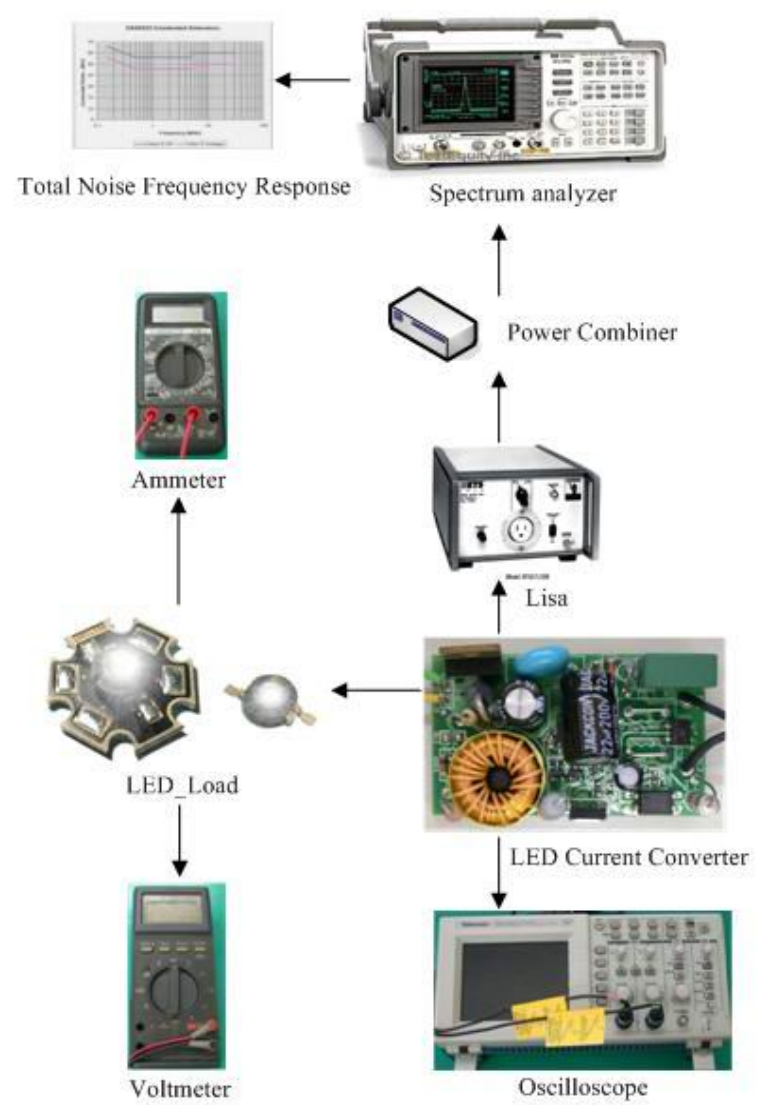

Fig.5 Test Equipments
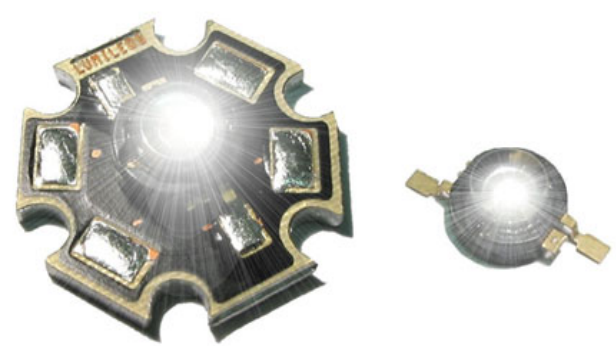

Fig.6 High-Flux White Light LEDs

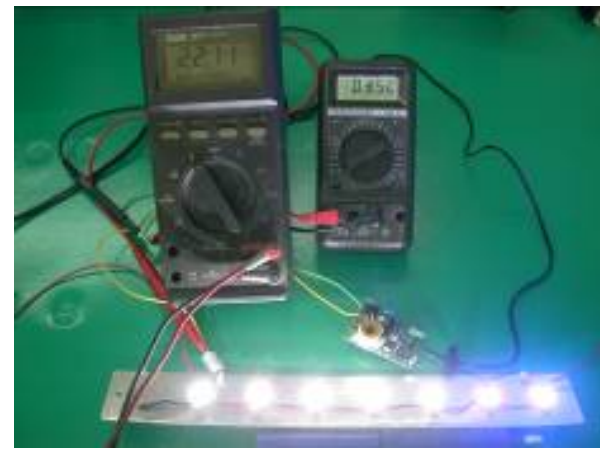

Fig.7 Photograph of Current Test for 7-High-Flux White Light LED

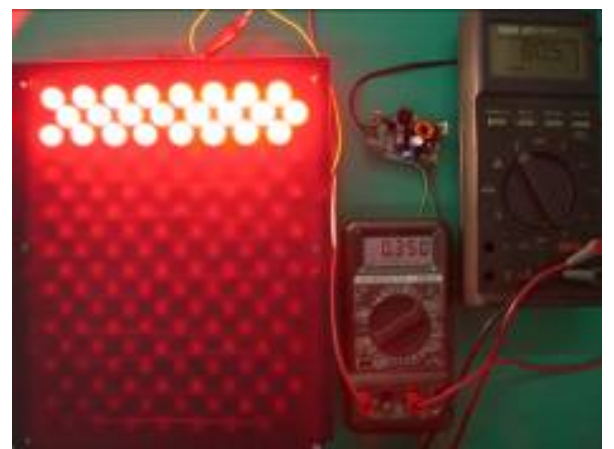

Fig.8 Photograph of Current Test for 24-High-Flux White Light LED

Table1 Data of Load test I

\begin{tabular}{|c|c|c|}
\hline \multicolumn{3}{|c|}{ Load test I } \\
\hline \multicolumn{3}{|c|}{ High Power Transformer turns ratio $97: 17$} \\
\hline Load & No Load & $\mathrm{LED} \times 7$ \\
\hline Input power (W) & 0 & 9.6 \\
\hline Output Voltage $\left(\mathrm{V}_{L}\right)$ & 23.01 & $22 \pm 2 \%$ \\
\hline Load current $\left(\mathrm{I}_{L}\right)$ & 0 & $350 \pm 0.5 \%$ \\
\hline Output power (W) & 0 & 7.7 \\
\hline Light Output (Lm) & 0 & 20 \\
\hline $\begin{array}{l}\text { Input/Output } \\
\text { Power ratio }\end{array}$ & & 0.8 \\
\hline
\end{tabular}


Table2 Data of Load test II

\begin{tabular}{|c|c|c|}
\hline \multicolumn{2}{|c|}{ Load test II } & $\mathrm{T}=25^{\circ} \mathrm{C}$ \\
\hline \multicolumn{3}{|c|}{ High Power Transformer turns ratio $97: 59$} \\
\hline Load & No Load & $\mathrm{LED} \times 24$ \\
\hline Input power $(\mathrm{W})$ & 0 & 35.8 \\
\hline Output Voltage $\left(\mathrm{V}_{L}\right)$ & 85.2 & $80.5 \pm 1 \%$ \\
\hline Load current $\left(\mathrm{I}_{L}\right)$ & 0 & $350 \pm 0.5 \%$ \\
\hline Output power (W) & 0 & 28.17. \\
\hline Light Output (Lm) & 0 & 20 \\
\hline $\begin{array}{l}\text { Input/Output } \\
\text { Power ratio }\end{array}$ & & 0.786 \\
\hline
\end{tabular}

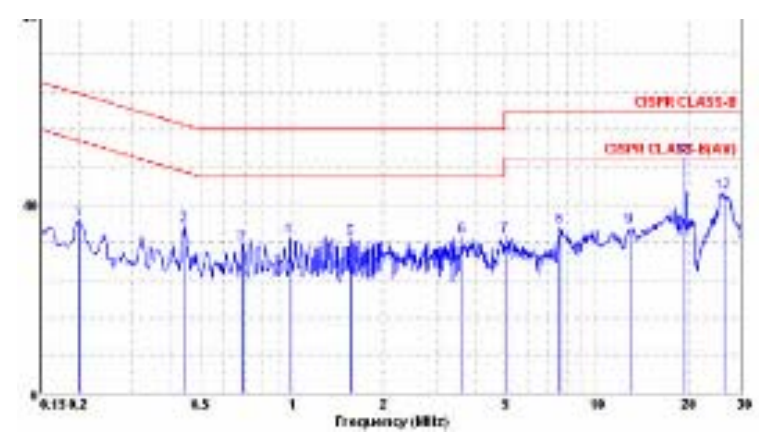

Fig.9 Test Result of Total Noise Frequency Response

\section{Conclusions}

In this paper, we propose a simplified forward power supply combined a smart current control and protection circuit for high power white light LEDs. The merit of the LED driver is with the System size miniaturization, the simple loop compensation and low cost circuit.

The experiment results shows the circuit can work well for different high power white light LED load and pass the electromagnetic interference test.

\section{References}

[1] Maxim-Dallas Semiconductor, "Why Drive White LEDs with Constant Current," Jun 03.2004.

[2] Lon-Kou Chang, and Hsing-Fu Liu, "A Novel Forward AC/DC Converter With Input Current Shaping and Fast Output Voltage Regulation Via Reset Winding” IEEE Transactions on industrial electronics, Vol. 52, No. 1, February 2005.
[3] Fazal A Talukdar, Biswajit Majuauk, harik Mukhcjer, and Sujit K Biswas,“A Clamped Forward Converter Power SuppIy with Inherent Active Power Factor Correction” IEEE 1999 International Conference on Power Electronics and Drive System, PEDS'99, July 1999, Hang Kong.

[4] Yilei Gu, Xiaoming Gu, Lijun Hang, Yu Du, Zhengyu Lu, and Zhaoming Qian, "RCD reset dual switch forward DC/DC converter", IEEE PESC '04. 35th Annual pp.1465-1469.

[5] Lon-Kou Chang, and Hsing-Fu Liu, "A Novel Forward AC/DC Converter With Input Current Shaping and Fast Output Voltage Regulation Via Reset Winding” IEEE Transactions on industrial electronics, Vol. 52, No. 1, February 2005. 